\title{
DA UNIVERSIDADE QUINHENTISTA DE PARIS PARA O MUNDO: CURRÍCULO E MÉTODO EM PETRUS RAMUS
}

Jorge Ramos do Ó ${ }^{1}$

Ana Luísa Paz ${ }^{2}$

\section{RESUMO}

Propomos uma discussão historicamente situada acerca da organização e administração, na cultura ocidental, de um saber inteiramente escolar, caracterizado pelos princípios da ordem e da uniformidade, e que se expressa em monografias - de tipo compendiário e manualístico -, produzidas para circular unicamente nos estabelecimentos de ensino. A análise recuará até ao espaço universitário do Renascimento e aos primeiros debates sobre a premência de um dispositivo de sistematização do conhecimento, onde Petrus Ramus aparece como uma personagem conceptual e onde se descobre um diagnóstico seminal assente sobre um gesto educativo como supondo uma dupla articulação: (i) o currículo é o invariante que permite racionalizar todo conhecimento através de disciplinas unidas num plano de estudos, ao passo que (ii) o método constitui a possibilidade de estabilizar e simplificar, de articular e graduar todos os

${ }^{1}$ Universidade de Lisboa (ULisboa), Instituto de Educação (IE), Unidade de Investigação e Desenvolvimento em Educação e Formação (Uidef), Lisboa, Portugal.

${ }^{2}$ Universidade de Lisboa (ULisboa), Instituto de Educação (IE), Unidade de Investigação e Desenvolvimento em Educação e Formação (Uidef), Lisboa, Portugal. 
conteúdos escolares.

Palavras-chave: currículo, método, Petrus Ramus, ramismo, pedagogia universitária.

\title{
DE LA UNIVERSIDAD QUINIENTISTA DE PARÍS PARA EL MUNDO: CURRÍCULO Y MÉTODO EN PETRUS RAMUS
}

\section{RESUMEN}

Proponemos una discusión históricamente situada sobre la organización y la administración, en la cultura occidental, de un saber enteramente escolar, caracterizado por los principios del orden y de la uniformidad, y que se expresa en monografías - de tipo compendiario y manualístico -, producidas para circular únicamente en los establecimientos de enseñanza. El análisis retrocede hasta el espacio universitario del Renacimiento y los primeros debates sobre la premura de un dispositivo de sistematización del conocimiento, donde Petrus Ramus aparece como un personaje conceptual y donde se descubre un diagnóstico seminal basado en un gesto educativo como suponiendo una doble articulación: i) el currículo es el invariante que permite racionalizar todo conocimiento a través de disciplinas unidas en un plano de estudios, mientras que (ii) el método constituye la posibilidad de estabilizar y simplificar, de articular y graduar todos los contenidos escolares.

Palabras clave: currículo, método, Petrus Ramus, ramismo, pedagogía universitaria.

\section{FROM THE 16TH CENTURY UNIVERSITY OF PARIS TO THE WORLD: CURRICULUM AND METHOD IN PETRUS RAMUS}

\begin{abstract}
We propose a historically situated discussion on the organization and administration, in western culture, of a specific knowledge of schooling characterized by the principles of order and uniformity and expressed in monographs - compendia and manuals - that was produced to exclusively circulate in educational institutions. This analysis reverts to Renaissance academia and the earliest debates on the urgency of developing a mechanism to systematize knowledge, a framework in which Petrus Ramus emerges as a conceptual persona. A seminal diagnosis based on the educational act as a double process was then developed: (i) the curriculum was to become an invariable that rationalizes all knowledge through the unification of disciplines in a single syllabus, whereas ii) the method came to mean the possibility of stabilizing and simplifying, assembling and grading, the totality of school contents.
\end{abstract}

Keywords: curriculum, method, Petrus Ramus, ramism, pedagogy in higher education. 


\section{DE L'UNIVERSITÉ DE PARIS AU XVIE SIÈCLE AU MONDE: CURRICULUM ET MÉTHODE EN PETRUS RAMUS}

\section{RESUME}

Nous proposons une discussion historiquement située sur l'organisation et l'administration dans la culture occidentale d'une connaissance entièrement académique, caractérisée par les principes d'ordre et d'uniformité, et qui s'exprime dans des monographies - de type compédiaire et manualistique - produites pour circuler seulement dans les établissements d'enseignement. L'analyse remonte à l'espace universitaire de la Renaissance et aux premiers débats sur l'urgence d'un dispositif de systématisation de la connaissance, où Petrus Ramus apparaît comme un personnage conceptuel et où un diagnostic séminal se fonde sur un geste éducatif assumant une double articulation: (i) le curriculum est l'invariant qui permet de rationaliser toutes les connaissances à travers des disciplines réunies dans un syllabus, alors que (ii) la méthode constitue la possibilité de stabiliser et de simplifier, d'articuler et de classer tous les contenus scolaires.

Mots-clés: curriculum, méthode, Petrus Ramus, ramisme, pédagogie universitaire. 


\section{INTRODUÇÃO: RAMISMO E A HISTÓRIA DO PRESENTE EDUCACIONAL}

Este artigo visa contribuir para uma discussão geral e historicamente situada acerca da organização e administração, na cultura ocidental, de um saber de base inteiramente escolar, estruturalmente caracterizado pelos princípios da ordem e da uniformidade, e que se expressa em monografias - de tipo compendiário e manualístico - produzidas para circular unicamente nos estabelecimentos de ensino. Para tanto, a a análise recuará até aos primeiros debates sobre a premência de um dispositivo de sistematização do conhecimento e levar-nos-á até ao espaço universitário do Renascimento. Aí havemos de descobrir um diagnóstico seminal assente sobre um gesto educativo como supondo uma dupla articulação: (i) o currículo é o invariante que permite racionalizar todo conhecimento através de disciplinas unidas num plano de estudos, ao passo que (ii) o método constitui a possibilidade de estabilizar e simplificar, de articular e graduar todos os conteúdos que são fornecidos aos alunos. A maquinaria escolar, assim concebida, tornar-se-ia de tal modo hegemónica, a partir da Modernidade, que não é fácil encontrar-lhe hoje a raiz e a discussão que a inteligibilizou. O objetivo deste artigo é, assim, fazer com que os debates acerca da mudança e da reforma sejam efetivamente capazes de se acercar da essência e dos pilares civilizacionais do modelo escolar, a fim de o transformar e ultrapassar.

Procuraremos deste modo trazer para a arena do conhecimento histórico um problema teórico - contribuir para a história do presente da escola que temos hoje, no sentido conferido por Michel Foucault em Vigiar e punir (1999 [1977]), e retraduzido para a história da educação em diversos trabalhos (inter alia, Ó, 2003) - através de uma metodologia de tipo essencialmente regressivo. Situar a discussão no momento da sua própria problematização histórica. Recuar o mais possível até aquele ponto em que as ideias e as soluções se apresentavam ainda como hipóteses em torno de autores que circulavam em contextos particulares. No caso, Petrus Ramus na Universidade de Paris do século XVI. Um ator e um 
palco no seu tempo, mas na verdade, o enunciar de uma perspetiva que se tornaria hegemónica com os séculos, cristalizando-se como sinónimo de currículo. Tratamos de fazer uma leitura em extensão e profundidade do conjunto dos seus escritos, procurando extrair desse acervo uma racionalidade acerca dos métodos e processos que tornam eficaz um ensino de massas. Como se em Ramus se inscrevesse não a distância, mas a emergência da nossa própria temporalidade educativa.

É no interior desta opção metodológica que o conceito de genealogia se nos impôs como a melhor ferramenta de investigação. Cabe assinalar que ele foi primeiro proposto em Genealogia da moral por Friedrich Nietzsche e, mais tarde, apropriado por Michel Foucault, que o teorizou e propôs como metodologia historiográfica. Trata-se de um procedimento que utiliza o conhecimento sobre o passado para compreender o presente, que assume uma ênfase na contínua interação durante a elaboração de teorias e de hipóteses e que procura refletir sobre o posicionamento do próprio investigador (VARELA, 2001, p. 108). Esta perspetiva almeja à identificação do momento de emergência de questões ou acontecimentos - na busca de uma intersecção ou irrupção, não se confundindo, portanto, com a busca da origem. Um dos aspetos fundamentais da genealogia é o facto de dar grande relevância a detalhes e acidentes, de modo a construir uma visão não-linear e não-teleológica do conhecimento, assumindo a descontinuidade dos eventos históricos (FOUCAULT, 1984, p. 77-84). A tarefa genealógica distingue-se da empreendida pela historiografia tradicional porque evita tanto o desejo de encontrar a essência metafísica de um objecto; ao contrário, procura estabelecer a proveniência das variadas práticas discursivas que informam a nossa matriz identitária. Perceber historicamente o que se tornou natural, inquestionável ou sempre lá.

Essas leituras de âmbito genealógico têm procurado sublinhar, recuperar e problematizar o facto de a escola da nossa modernidade ser, na verdade, o equivalente a uma manta de retalhos, de tal modo ela é constituída de ideias e práticas heterogéneas e mesmo contraditórias entre si, que se foram justapondo, 
adaptando e hibridizando, até se naturalizarem e surgirem na forma que apresentam hoje. A recuperação dos contextos e das ideias que originalmente compuseram a nossa moderna escolarização permite, no nosso entender, relançar o rigor historiográfico dos problemas educativos, como também interferir na capacidade de pensar e intervir no espaço público, de modo crítico, consequente e mais capacitado. Neste caso, mostrando que a escola e o quadro de pensamento a ela associada remete para formações discursivas outras, que pouco têm que ver com os problemas da sociedade atual, e que, liminarmente, a ideia de currículo que estamos continuamente a impor às crianças, jovens e académicos é altamente contingente e pode, a qualquer momento, ser retomada noutro rumo.

Toda a cultura pedagógica e escolar de que somos herdeiros é tributária da noção de ordem. Ora, ela seria intensamente problematizada na Universidade de Paris a partir da primeira metade do século XVI. Foi de fato nesse contexto preciso, pela primeira vez centrado no desígnio de alargar a escolarização fazendo-a sair dos círculos restritíssimos das organizações religiosas e da aristocracia europeia da Idade Média e do Renascimento - que se desbloqueou aquilo a que poderemos chamar de pedagogização dos conhecimentos dominada pelo objetivo maior do seu disciplinamento interno dos conteúdos ministrados e que os manuais escolares tão bem expressam. Com este ponto de partida específico procuramos atender a um grande consenso político-social da nossa civilização que postula a administração de um único corpus de saber sempre que se trata de massificar e de abrir as portas da escola a novas camadas da população. E desse modo contribuir, também, para uma discussão inteiramente da atualidade, do nosso tempo, e em grande parte ainda por fazer, sobre a separação entre a cultura escolar e a cultura científica, o fosso tão naturalizado entre ensinar e investigar.

Não há como evitar reconhecer que a instituição escolar encontra na ideia de percurso orientado - não importa se para virtude moral ou para o conhecimento científico - o seu mais precioso património. Método devolve-nos 
continuamente a ideia de um traçado e quase sempre conduz a um final já previamente desenhado e testado. A que o aluno se vá formando desde os bancos da escola até à universidade apenas perguntando apenas aquilo que mais rapidamente nos conduz a uma resposta que está sempre na posse do professor. Escreveu Descartes (1596-1650) (1989 [1628], p. 8) nas suas Regras para a direção do espírito:

\footnotetext{
Entendo por método um conjunto de regras certas e fáceis, que permitem a quem exatamente as observar nunca tomar por verdadeiro algo de falso e, sem desperdiçar inutilmente nenhum esforço da mente, mas aumentando sempre gradualmente o saber, atingir o conhecimento verdadeiro de tudo o que será capaz de saber.
}

Esta é uma definição atemporal porque exprime com inteira clareza a rotina de eficiência a que o conceito de método ainda nos submete - quando pensamos nele temos geralmente em mente uma série de passos ordenados que se devem percorrer de modo a produzir, com a maior segurança possível, um efeito desejado.

Em todo o caso, o tremendo interesse que associou a palavra método à especificação do processo de ensinar, e por isso mesmo aos passos que deviam ser dados numa ordem determinada para aceder a um conhecimento já estabelecido e fundamentado, é anterior em cerca de duas gerações ao tempo em que viveu o autor do Discurso do método e cuja primeira edição data de 1637. De facto, na cultura universitária de Quinhentos, methodus foi deixando de ser uma espécie de apêndice de outros termos como ars, clavis, medius, ou mesmo empereia, para se estabilizar enquanto sinónimo de um experimento positivamente controlado e, por essa razão, passou a ser associado com scientia, doctrina, via compendiaria e até compendium. É da segunda metade dessa centúria que provém a tradição incorporada nas nossas instituições de educação e ensino segundo a qual doutrina é a própria ciência ou que ensinar uma coisa é o mesmo que demonstrá-la e prová-la. Desde então, método quer significar a 
ordem encontrada no interior de uma ciência perfeita e completamente organizada ou, ainda, a ordem de apresentar um assunto enquanto se ensina esse mesmo assunto. O tempo da escola corresponde, assim, à manutenção continuada de um dos pilares sobre que assenta a nossa própria nossa civilização. Falar-se-á aqui dessa conhecida disposição à prática que, através de rotinas de orientação e coordenação, de alinhamento, arrumação, seriação e enfileiramento gradual, vão acomodando, dirigindo e uniformizando tanto dos corpos de conhecimento quanto, no interior da classe, os próprios corpos dos sujeitos aprendentes.

Petrus Ramus (1515-1572) aparece neste texto como alguém cujo discurso exprimiu diagnósticos e soluções que se tornariam não apenas reconhecidas mais tarde, mas se transformaram numa verdadeira evidência sempre que alguém discorre acerca da noção de um saber universal - a um tempo segmentado por províncias disciplinares, mas também interligado pela utopia totalizante do enciclopedismo - e sua administração às consciências e aos corpos ainda em formação. A notoriedade de Ramus na filosofia, na teologia e na literatura do Renascimento foi assaz demarcada na época em que viveu, tendo mesmo desencadeando as mais extremadas reações. As ondas de impacto da sua obra não têm cessado de se fazer sentir, embora ele mesmo tenha visto os seus livros banidos e queimados, tudo culminando com o seu assassinato em Paris a 26 de agosto de 1572, na sequência do massacre dos huguenotes na Noite de São Bartolomeu. A sua trajetória académica exprimiu-se no quadro das lutas intestinas da Igreja Católica com as fações protestantes, das sucessivas tomadas de poder na corte do Reino francês e, sobretudo, das tentativas de imposição da Universidade de Paris face à liberdade de ensino em vigor no Collège de France.

$\mathrm{Na}$ economia do argumento que aqui queremos desenvolver Ramus funciona, já se percebeu, como a personagem conceitual do devir da maquinaria escolar subsequente da chamada escola para todos, porquanto muitas das suas reflexões convergiram para inteligibilizar a currículo como método e o método como via de atalho para acesso ao conhecimento útil. Ora, essa tese não cessou 
reverberar e a desdobrar-se em seguida, fosse mais diretamente pelos seus discípulos, fosse igualmente em testemunhos de mil outras procedências, até à nossa atualidade. O ramismo teve, desde logo e como ponte de passagem mais fulgurante, o conhecido ideal pansófico do século XVII, estabelecido pelo cientista e pedagogo Comenius (1592-1670), autor da Didactica Magna, que se destacou na defesa desse ideal, prenhe de consequências diretas para o ensino praticado entre os séculos XVIII e XX: o de que não é apenas possível mas efetivamente necessário unificar todos os conhecimentos e as habilidades humanas, a fim de tudo ensinar a todos por meio de um método universal.

\section{O RAMISMO: PRAGMATISMO PEDAGÓGICO, VULGARIZAÇÃO DO CONHECIMENTO E MASSIFICAÇÃO DO ENSINO}

Há que ter desde logo bem presente que quando apontamos o extraordinário impacto de Ramus não estamos a querer identificar a marca distintiva de um tipo de humanismo clássico ou de uma escola literária, teológica ou filosófica. A sua relevância para a história intelectual advém do facto das mais de cinco dezenas de publicações que assinou - além de outras em parceria, sob pseudónimo ou dadas à estampa após o seu desaparecimento - não configurarem exatamente uma teoria, mas remeterem, antes, para a realização de um conjunto de procedimentos de tipo cognitivo-adaptativo. O ramismo deve aliás ser considerado mais como um movimento, na medida em que se enraizou numa incubadora de hábitos processados ao longo dos séculos de existência de toda uma tradição educacional, e cuja especialização se centrou em determinados conceitos e em modelos espaciais simples para a compreensão dos processos mentais e comunicacionais. Neste sentido, vale enquanto registo, sintoma e epifenómeno de um processo de busca de eficácia pedagógica que afetou todo o ocidente e como tal deve ser compreendido. Walter Ong (1983 [1958], p. 7), a quem se deve o estudo seminal sobre o pensamento de Ramus, caracteriza-o 
como mais uma figura típica do século XVI preocupada com a linguagem e as tradicionais artes da expressão, a gramática, a retórica e a lógica, a meio caminho entre a linguística e a metafísica. E ao ramismo toma-o como "o itinerário central sobre o qual a tradição da retórica ciceroniana e a tradição da lógica escolástica se movimentam ao reorientarem-se para o mundo moderno".

Sublinhe-se que Ramus fora amiúde considerado pelos seus próprios contemporâneos como um usuarius ou usurarius, alguém que se alimentava e beneficiava do capital intelectual construído por terceiros. Estamos em crer que o epíteto, então também já claramente depreciativo, deve ser interpretado enquanto mais um sinal, e de resto um importante sinal, da construção social dessa clivagem entre quem ensina e quem produz conhecimento. É como se o ramismo tivesse adquirido uma extraordinária importância, podendo mesmo falar-se de um autêntico fenómeno cultural internacional - as edições e reedições das suas obras sucederam-se em elevadíssimo ritmo entre 1540 e 1611, um pouco por toda a Europa, de Paris a Londres, de Frankfurt a Colónia, de Cambridge a Edimburgo e a Amesterdão, de Estrasburgo a Salamanca e a Praga, de Oxford até às colónias britânicas na América, especialmente em Harvard -, mas essa sua constante presença estava destinada a tornar-se anónima, melhor dito, a ser de tal maneira aceite e incorporada que se tornaria impercetível. Na verdade, a influência faz-se sentir nesse grande depósito que é constituído pela literatura de manuais escolares universitários e de ensino secundário. O ramismo permanece como aquela invisível ponte que une as nossas ideias mais familiares com uma herança universal e atemporal de acesso ao saber, um quadro de referência, um instrumento de conhecimento, de pensamento e de sensibilidade intelectual. Constitui uma importante parte dos tendões e dos ossos da nossa civilização, porque se dispersou no interior de uma longa formação discursiva que inteligibiliza as disciplinas enquanto sistemas de divisões, preceitos e regras organizadas de acordo com as lógicas do método e, portanto, independentes das autoridades superiores, clássicas ou coevas, que internamente vão estruturando, desenvolvendo e relacionando os respetivos conteúdos de saber. Não se perca de vista que o conceito de método viria a ser o item mais famoso de todo o repertório 
de Ramus, tendo sido considerado pelos admiradores o maior mestre do atalho que o mundo até então conhecera. Por intermédio da sua intervenção, estamos certos que fica mais palpável o ponto de vista que nos diz que o mundo da pedagogia é menos o da criação do que o da absorção e da adaptação.

Distinguiu-se dos demais compendiadores do seu tempo por ser capaz de editar uma série completa de manuais escolares atinentes a cada uma das sete artes liberais e em que o respetivo estudo se deixava dominar pela utilidade prática. Pela enorme difusão que conheceram, devem mencionar-se os títulos de dois manuais. O mais importante deles, Dialectique, e que traduz grande parte das suas preocupações pedagógicas no ensino da lógica experimentadas ao longo dos anos 40, seria publicado em 1555 e rompeu também com a tradição escolástica não apenas na conceção de ensino que explicitava, mas também por ter sido escrito em língua francesa; embora no ano seguinte tenha surgido uma versão latina Dialecticae libri duo, a qual conheceu centenas de edições, tendose disseminado em escolas e em universidades europeias, sobretudo em países protestantes. Walter Ong (1983 [1958], p. 296) contabilizou 150 edições e adaptações desta obra apenas no período compreendido entre 1555 e 1600, ficando assim bem patente a aceitação que alcançou entre os professores. O outro, um manual de retórica, Institutiones rhetoricae, aparecido ainda em 1545, também conheceu grande sucesso editorial e educativo. O objetivo maior de Ramus, o da reforma do currículo das faculdades de artes, operacionalizou-se em larga escala com esta dupla de manuais. Por seu intermédio, passou na realidade a dispor-se de um conjunto de preceitos muito homogéneo nas duas principais disciplinas do trivium, os quais foram ainda concebidos e apresentados por forma a impor-se naturalmente na mente e na memória dos alunos, uma vez que na respetiva conceção ambos se submeteram à necessidade de articular o princípio da coerência estrutural interna com o da ordem sequencial na apresentação dos assuntos. Nos anos 60, Ramus dedicar-se-ia às demais disciplinas, tentando que elas obedecessem aos mesmos quesitos da simplicidade, exequibilidade, eficiência e economia. É a partir dele que, de facto, se pode começar a falar de uma pedagogia utilitária (ONG, 1983 [1958], p. 9-16; HOTSON, 2007, p. 5 e 50; 
SELLBERG, 2016, p. 4).

A historiografia retém no essencial duas grandes explicações para o impacto do ramismo e ambas se ligam entre si. Uma primeira associa-o à evolução da imprensa, condição absoluta, como é sabido, para o desenvolvimento de novas técnicas de apropriação e disseminação do conhecimento. Os avanços da tipografia da sua época permitiam que cada página passasse a conter os lugares e a armazenar argumentos, que assim se tornavam visualmente apreensíveis e espacialmente manobráveis. Ao passo que se multiplicavam as edições e aumentavam as tiragens, os manuais foram-se deixando graficamente dominar pela lógica tópica antiga e que os homens do Renascimento tão bem souberam explorar. Ramus esteve no coração deste empreendimento, obstinado que se manteve em mostrar como o texto clássico se podia substituir por uma metodologia que o sistematizasse. Um livro não passava, para ele, de um arranjo de materiais e esta posição extrema granjeou-lhe em vida também a oposição de vários muitos humanistas, os quais, valorizando em todas as circunstâncias a fonte originária antiga, filosófica ou literária - pela pluralidade de sentidos e de modalidades de apropriação que oferecia ao leitor -, defendiam que os manuais de Ramus apenas deviam servir para o estudo privado ou, quando muito, para a introdução geral aos autores e aos problemas a serem trabalhados nas salas de aula. Cabe então compreender que foi no contexto próprio da produção manualística que o conceito de método ganhou uma efetiva significação e se afirmou, diria que todo poderoso, no território educacional. Método, para Ramus, era o instrumento que lhe permitiria governar a feitura de um livro. Método passa a ser interior mesmo dos livros escolares.

Ainda sobre este particular, retenha-se que os seus manuais se foram tornando espacialmente organizados justamente durante esta época em que as tipografias começaram a perceber que o formato da impressão envolvia um compromisso com a visão assaz diferente daquele que era exigido pelo formato de um manuscrito. Com efeito, observa-se em Ramus uma progressão regular desde as primeiras edições - em que o texto era ainda uma espécie de massa de 
protoplasma tipográfico, sem títulos autónomos, sem divisões de capítulos, com poucos parágrafos e quase nenhum sentido de disposição espacial - até às últimas publicações, que surgem já com cabeçalhos centrados, títulos corridos, e outras técnicas de disposição tipográfica, em claro compromisso com o espaço circunscrito pela página. Percorrendo o estádio em que um livro podia ser assimilado pelo simples facto de ser lido (e pensado como para ser lido em voz alta), até ao estádio tipográfico definitivo, por meio do qual um livro podia ser (pelo menos, em parte) assimilado pelo simples facto de ser olhado, é cada vez mais evidente que a estruturação do discurso se desenvolvia em conexão com a reelaboração das conquistas que a imprensa ia permitindo. $\mathrm{O}$ asseio diagramático que a imprensa estava a transmitir para o domínio das ideias permitiria libertar o livro do mundo do discurso e transformá-lo num objeto concreto, numa caixa com superfície e conteúdo, um locus real. Na era pósGutemberg em que o ramismo floresceu, o termo conteúdo, aplicado ao que se encontra dentro da produção impressa, adquiriu um estatuto que nunca antes lhe fora concedido. Quando os manuais escolares foram introduzidos na sala de aula, tornou-se então possível, para o mestre-escola ou para o conferencista universitário, focar o todo da economia pedagógica no arranjo espacial de materiais perante o aluno ou o pupilo. Olha para a página sete, linha três, a quarta palavra - este tipo de diretiva tornou-se uma rotina quotidiana na cultura tipográfica. Milhares de escolares foram doravante induzidos a uma compreensão da linguagem e do mundo à sua volta através de um caminho que se fazia, conjuntamente, através de textos individuais arranjados de acordo com padrões espaciais idênticos. Ora, tais diretrizes eram impossíveis antes do advento da imprensa. Encontrar um lugar num livro constituía nesses tempos um problema sério quando se estava frente a um exemplar copiado à mão. E os livros continuavam a ser registos de palavras, auxiliares para o chamamento do som (lia-se em voz alta enquanto se lia para si mesmo), ao invés de lugares que continham coisas bem localizadas. Destarte, Ramus foi um ator privilegiado desse movimento de fuga em relação a um conceito de conhecimento dependente da oralidade, do diálogo e da disputa - esse mundo antigo da sonoridade e que 
vivia da presença do sujeito - em direção a um novo conceito de conhecimento que se associaria crescentemente a uma realidade silenciosa e que se vai enchendo de objetos concebido em termos visualistas e diagramáticos para uso individual. Os livros escolares, em lugar de dizerem a verdade, passam a conter a verdade. Esta análise corresponde no essencial à tese expressa por Walter Ong em Ramus method and the decay of dialogue.

A associação entre Ramus e a massificação do ensino é a segunda grande evidência histórica. A difusão da sua pedagogia esteve relacionada com o facto de os adolescentes passarem a dispor de matérias organizadas segundo uma ordem e uma metodologia concebida com o propósito de as impor naturalmente à mente e à memória. Howard Hotson mostra em Commonplace learning: Ramism and its German ramifications (1543-1630) que foram os estudantes, mais até do que as inovações permitidas pela imprensa, os grandes responsáveis pelo alastrar do ramismo. As quatro gerações subsequentes ao tempo em que ensinou defenderam à outrance a necessidade de fazer prevalecer no currículo escolar as características dominantes da proposta de Ramus, desde muito cedo abraçada pelos jovens como uma pedagogia subversiva, no sentido em que constituía a que melhor se adaptava às suas necessidades, meios financeiros e capacidades intelectuais. Por isso, ele terá sido tão controverso e perseguido quanto popular. A sua ação inscreve-se nesse momento histórico particular em que se assistiu a uma forte pressão da procura sobre as elites académicas, traduzida na demanda de um novo currículo. Esta mudança ficou, no essencial, a dever-se a uma inversão no destino profissional dos alunos da faculdade de artes, que tradicionalmente devia formar para o prosseguimento de estudos em teologia, medicina ou jurisprudência, mas não o lograva atingir, posto que à época a larga maioria dos alunos interrompia os estudos a meio para abraçar uma carreira na Igreja. Ramus terá identificado a falta de eficiência do currículo escolástico e tentou acompanhar os sinais dos novos tempos que reclamavam pela introdução ou pelo maior desenvolvimento nas disciplinas mais caras aos humanistas - a história, a literatura, a retórica e a ética. Tal como o concebia, o curso da faculdade das artes deveria fornecer uma espécie de filosofia prática para adolescentes, 
submeter-se aos critérios de simplicidade, inteligibilidade e aplicabilidade. Adotou como seu lema a famosa frase de Virgílio labor improbus omnia vincit (o trabalho supera todos os obstáculos), para sustentar que, com maior aplicação e a devida direção, todos os alunos podiam atingir rapidamente os objetivos a que se propusessem. Ele mesmo havia sido um estudante pobre que ascendera socialmente pela via da educação escolar. A promessa de um maior retorno do investimento feito na educação escolar - mais disciplinas e conhecimentos adquiridos numa fração de tempo menor - é evidente que agradava às famílias e ia, ainda, ao encontro da proposta calvinista que amalgamava os ideais de contenção, voluntarismo, utilitarismo e realismo. Esta convergência fez com que o ramismo se transformasse num fenómeno cultural internacional da maior envergadura.

\section{ANTI-ARISTOTELISMO E REFORMA DO CURRÍCULO}

Ramus tornou-se professor universitário no Collège de Mans logo após se ter formado no de Navarra, com a idade de 21 anos. Nessa ocasião, terá lançado o mote do seu combate em favor da reforma educacional quando, numa disputa que durou um dia inteiro e da qual saiu aprovado, defendeu a tese segundo de que tudo quanto Aristóteles havia escrito estava errado. Tornar-se-ia desde então um defensor da liberdade académica na interpretação de qualquer autor, o que naturalmente lhe granjeou notoriedade, mas o colocaria também numa trajetória de alto risco entre os seus pares. Passou depois anos a lecionar noutros estabelecimentos congéneres, os Collèges Ave Maria e de Presles, chegando mesmo a dirigir este último e a conseguir, com as inovações aplicadas ao ensino das várias artes liberais, afirmá-lo como um dos mais prestigiados de toda a universidade em meados de Quinhentos. Em Presles começou a fazer parceria, entre outros, com Omer Talon (1510-1562) - com quem viria também a publicar vários livros - e, pela primeira vez na Universidade de Paris, os autores gregos e 
latinos foram lidos ao mesmo tempo, uma vez que o estudo da eloquência e da literatura clássica se juntava ao da filosofia e o dos poetas ao dos oradores. Saiu de Presles, corria então o ano de 1552, para se tornar no primeiro professor de eloquência e filosofia do Collège Royal, mais tarde o Collège de France, instituição criada uma vintena de anos antes por Francisco I como alternativa à Universidade de Paris. Em 1562 publicou em língua francesa um livro, dedicado ao Rei, no qual procurou sistematizar as suas posições críticas e que se intitula Advertissements sur la reforme de l'Université de Paris.

O permanente anti-aristotelismo de Ramus não terá derivado de um insight analítico, resultado do convívio assíduo com as obras do filósofo grego, mas tão somente do firme propósito de reformar o currículo e transformar as práticas correntes do ensino pré-universitário e universitário em que fora educado e no qual permanecia enquanto docente. Uma das suas primeiras publicações, saída em 1543, Aristotelicae Animadversiones: Dialecticae institutiones, constituiu já um feroz ataque aos discípulos tidos como "bárbaros" do filósofo grego, por protagonizarem à época as mais "estéreis e ruidosas disputas" e validarem de forma mecânica as opiniões estabelecidas sobre o autor da Poética. Era facto que ninguém, ao tempo, podia passar pelas faculdades de artes sem estudar e se conformar com as interpretações feitas sobre Aristóteles, o autor-herói por excelência. Ramus não raro acusou os seus colegas de não serem dignos do mestre, posto que o próprio Aristóteles filosofara "com inteira liberdade e até contra Platão, seu próprio professor" e sempre apresentara "os dois lados da questão em permanentes discussões" com os seus discípulos. O problema não estava, portanto, na arte lógica do pensador grego, mas no dogmatismo imposto pelos seus "intérpretes" posteriores (RAMUS cit. SELLBERG, 2016, p. 13). Um dos inimigos de Ramus, porventura o mais implacável e enérgico de todos quantos conheceu em vida, Jacques Charpentier (1524-1574), professor do Collège de Boncourt, organizou a sua ofensiva nos mesmos termos, acusando-o de ensinar Aristóteles livremente e a partir de ideias próprias, deixando de lado a metodologia tradicional de seguir o texto palavra por palavra. É neste particular que a figura de Ramus nos surpreende e nos obriga a 
recusar a linearidade da interpretação histórica: foi um ator social capaz de articular uma crítica à prática pedagógica dominante, assumindo o risco de ser classificado de heterodoxo e expondo-se ao banimento, mas as ideias radicais que absorveu e de que se fez porta-estandarte adquiririam uma inusitada resiliência, sobrevivendo, uma após outra, a todas as vagas reformadoras que desde então têm assolado a arena educativa. A procura da arqueologia da ortodoxia educacional dos tempos modernos há de conduzir-nos, fatalmente, ao ramismo.

Várias das considerações críticas foram ainda desenvolvidas e ficaram expressas em Scholae in liberales artes, livro que Ramus fez publicar no ano de 1569 e onde congregou, por tópicos e índices detalhados, os seus manuais de gramática, dialética, retórica, ciências da natureza (physicae), metafísica e matemática. Explicitou aí a sua enorme preocupação com a falta de eficiência e eficácia do ensino, que ele próprio já testemunhara enquanto estudante. No cerne do problema estava, outrossim, o legado de Aristóteles - não tanto o metafísico e teológico - mas o da lógica, e que o tornara num autor temido pelas subtilezas a que havia chegado na análise das operações psicológicas. Tudo no ensino da lógica parecia a Ramus eivado de formalismos absurdos e fora de qualquer relação com as necessidades da vida real. O seu relato confessional é tão irónico quanto desassombrado. Enfrentou os processos e as rotinas da academia, não tendo receio de a descrever como estando consagrada em lançar sobre o pensamento um manto de esterilidade, obscurantismo e falsidade. O desafio à autoridade universitária, feito em nome da procura do melhor método, levou-o a descobrir em Galeno, Platão e Sócrates o melhor contraponto com a atualidade. A descrição que nos faz da universidade do seu tempo de estudante destinava-se a reforçar a tese segundo a qual a reforma da educação só podia legitimamente afirmar-se pelos princípios da transparência e da simplicidade. Parece organizarse no discurso reformador de Ramus a noção de que a prioridade da pedagogia não deve estar no que é mais conhecido mas tão somente no que é mais claro.

Nunca entre os clamores do colégio onde eu passei tantos dias, meses, anos, alguma vez ouvi uma única palavra sobre as aplicações da lógica. 
Tinha então fé (o académico deve ter fé, segundo Aristóteles) que não era preciso preocupar-me com o que é a lógica e qual a sua finalidade, mas que ela dizia respeito apenas à criação de um motivo para os nossos clamores e para as nossas disputas. Eu, por isso, disputava e clamava com todas as minhas forças. Se estivesse na sala de aula a defender uma tese de acordo com as categorias, acreditava que era meu dever nunca ceder ao meu adversário, mesmo que ele estivesse cem vezes certo, e ir buscar alguma distinção muito sutil, a fim de obscurecer toda a questão. Por outro lado, se fosse eu o disputante, toda a minha atenção e esforços não tendiam a iluminar o meu adversário, mas a vencê-lo por algum argumento, fosse bom ou mau: assim mesmo fui ensinado e dirigido. As categorias de Aristóteles eram como uma bola que damos para as crianças brincarem, e que era necessário recuperar com clamores quando a perdíamos. Se, por outro lado, devemos obtê-la, não devemos através de qualquer protesto permitir a sua recuperação. Estava então persuadido de que toda a dialética se reduzia a disputar com altos e vigorosos gritos. Talvez me pergunteis quando e como finalmente me deparei com um método melhor. Vou dizer-vos livre e abertamente, a fim de que, se o remédio que me resgatou puder ser útil na vossa situação, o possais usar livremente. Não procuro de todo convencer-vos pelo meu argumento; apenas desejo explicar simples e diretamente como emergi dessa escuridão. Após ter devotado três anos e seis meses à filosofia escolástica, de acordo com as regras da nossa universidade; depois de ter lido, discutido, e meditado sobre os vários tratados do Organon (pois todos os livros de Aristóteles, especialmente aqueles que tratam de dialética, eram lidos e relidos durante o curso de três anos); mesmo depois, digo ainda, tendo colocado em todo esse tempo, e calculando os anos em que estive totalmente ocupado no estudo das artes escolares, procurei aprender como podia, como consequência, aplicar o conhecimento que tinha adquirido com tanto esforço e fadiga. Logo percebi que toda essa dialética não me tinha tornado mais conhecedor em história e no conhecimento da antiguidade, nem mais hábil na eloquência, nem melhor poeta, nem mais sábio em nada. Ah, que assombro, que tristeza! Como acusei as minhas deficiências! Como lamentei o infortúnio meu destino, a esterilidade de uma mente que depois de muito trabalho não poderia reunir ou mesmo perceber os frutos dessa sabedoria que alegadamente se encontrava tão abundantemente na dialética de Aristóteles!

Finalmente, encontrei um livro de Galeno sobre o pensamento de Hipócrates e Platão. Esse paralelo entre Platão e Hipócrates deu-me grande prazer, mas inspirou-me um ainda maior desejo de ler todos os diálogos de Platão que tratavam de dialética. Foi então, para dizer a verdade, que cheguei ao tão desejado porto... Aquilo que especialmente apreciei, e mesmo gostei, em Platão, foi o método pelo qual Sócrates refutou falsas opiniões, tentando, antes de mais, despertar os seus ouvintes acima dos sentidos, preconceitos e tradições dos homens, a fim de os encaminhar para o seu próprio senso natural de direito e de liberdade de julgamento. Pareceu-lhe insano que um filósofo pudesse 


\begin{abstract}
permitir-se agir de acordo com as opiniões das massas, que no mais das vezes são falsas e enganadoras, ao invés de se aplicar a verificar apenas os factos e as suas verdadeiras causas. Em suma, comecei a dizer a mim mesmo (deveria ter hesitado em dizê-lo a outrem): 'Bem, o que me impede de 'socratizar' um pouco, e de examinar, independentemente da autoridade de Aristóteles, se a doutrina da sua dialética é a mais verdadeira e útil? Talvez esse filósofo tenha abusado de nós pela sua autoridade, e, nesse caso, eu não precisaria de estar surpreendido por ter estudado pelos seus livros sem deles tirar qualquer lucro, quando eles não continham nenhum... E se essa doutrina fosse uma desilusão?' (RAMUS cit. GRAVES, 1912, p. 23-25, grifo do autor).
\end{abstract}

Mantendo sempre acesa a crítica acirrada ao dispositivo adaptativo aristotélico, constantemente reativado pela prática escolástica da disputa segundo o qual os saberes se formam nos espíritos pela sua aquisição e que o conhecimento se atinge da sua constante frequentação -, Ramus é por certo umas das mais longínquas personalidades a defender a fusão do sujeito com o objeto do saber quando, texto após texto, livro após livro, nos vai reafirmando que o espírito tem a capacidade natural de conhecer todas as coisas, desde que, para tanto, seja bem comandado e se disponha realmente a compreendê-las. Os seus escritos procuraram até à exaustão, e não obstante as evidentes oscilações e até contradições manifestas que ocorrem no seu interior, operacionalizar a grande articulação da cultura escolar moderna e contemporânea: a que associa o inatismo com a necessidade de direção permanente das almas em formação. Como muitos dos seus contemporâneos, Ramus usava ars como sinónimo de scientia, disciplina, methodus, professio, e até virtus e sapientia, querendo desse modo também significar que arte é uma forma de ensinar; mas, em rotura radical com muitos deles, propugnou por uma fórmula universal, pela existência de um método dialético comum de ensinar fácil e claramente a todos os alunos os vários ramos do conhecimento. Se cada uma das sete artes liberais tinha o seu domínio e formas de aproximação aos respetivos objetos, era em última análise a lógica ou a dialética, a sua especialidade - que devia prevalecer no seu ensino. Não deixou de insistir que cabia efetivamente esta disciplina suportar a própria fabricação da consciência humana e que dela se podia extrair uma teoria da 
invenção de aplicabilidade universal. "Os fins e os processos de ensino de todas as artes podem ser separados uns dos outros", assentia Ramus, "mas devem ser reunidos na sua utilidade" (ONG, 1983 [1958], p. 135).

Novamente em Scholae in liberales artes, e prosseguindo a sua busca da fórmula universal de ensino, Ramus confessou ter encontrado em Rodolfo Agrícola (1444-1485) e Jean Sturm (1507-1589) os seus dois intercessores por excelência. Ainda estudante universitário percebera que o autor de De inventione dialectica havia sido o primeiro professor, "desde os bons tempos da Grécia e de Roma, a recuperar a utilização de lógica e a convidar os jovens a procurar os poetas e oradores, não só como os mestres de estilo e de eloquência, mas também como modelos de raciocínio e da arte de pensar". Já a Sturm, formado na escola de Agrícola e seu muito venerado professor, eram inteiramente devidas a honra e a glória de ter conseguido com que Paris reconhecesse, "pela primeira vez, as esplêndidas aplicações da lógica" e ter conseguido animar "na universidade um incrível ardor por ela", entre os quais ele se considerava apenas mais um fervoroso soldado (RAMUS cit. GRAVES, 1912, p. 17). E, na realidade, foi a Sturm que ficaram a dever-se os primeiros esforços no sentido de se encontrar um compromisso da tradição tópica científica com a pedagogia prática. $\mathrm{O}$ terreno para o empreendimento cartesiano posterior ficou a partir daqui bem trabalhado, porquanto a pedagogia de Sturm procurou, na emaranhada situação em que se encontrava a questão do conhecimento à época, mostrar que a claridade e a inteligibilidade podiam constituir uma e a mesma coisa: o bom professor seria aquele que conseguisse fazer trabalhar no espírito dos seus alunos tudo o que lhes estivesse a ensinar. Nos comentários que em 1539 fez às Partitiones oratoriae de Cícero, Sturm definiu o método como a modalidade certa, concisa, correta e compreensível de ensinar cada uma das várias artes liberais. Para tanto, distinguiu três caminhos ou vias que lhe pareciam equivaler a outros tantos métodos: caminhar do geral para o particular e assim chegar à análise; proceder exatamente no caminho inverso, isto é, fazer a síntese; dividir por fim todas as definições nas suas respetivas partes (MACK, 1995, p. 350). Claramente, estes três procedimentos derivavam da arte médica de Galeno, cujos métodos de 
ensinar - e não de curar - articulavam análise, síntese e definição. Se a dialética já então se equiparava à própria ideia de ensino, sem dúvida que com Sturm o substantivo método passou a ligar-se ao caminho mais célere para se investigar e obter uma explicação sobre qualquer assunto. Encontrou, assim, na dialética a faculdade de examinar, julgar e discursar acerca do que uma a coisa é, e de que tipo deve ser de cada vez que é proposta como matéria para ser investigada ou transmitida. Quando se viu continuamente associado à lógica tópica de Agrícola e à respetiva explicação dos lugares, o seu método fixou-se na linguagem pedagógica como o instrumento que abre a passagem, corta e constrói a estrada do pensamento. Mas neste particular da reivindicação de uma herança e partilha intelectual, faltou sem dúvida a Ramus invocar a intervenção de uma terceira figura e sua contemporânea, Melanchthon (1497-1590), porque nos manuais de dialética deste existia sempre uma secção inteiramente dedicada ao método, entendido como a parte judicativa da dialética. Melanchthon focou-se em ordenar os itens que pertencem a determinadas categorias e que, assim, podiam deixar de ser vistos enquanto predicados para se passarem a entender como caixas, como os contentores mesmos dos lugares. A noção segundo a qual método corresponde à inscrição de uma forma direta para investigar ou explicar qualquer assunto também a ficamos em boa parte a dever a ele. Desde Melanchthon que qualquer palavra pode ser questionada sucessivamente acerca do seu significado, da existência da coisa para a qual remete, das partes que a compõem, bem como as várias espécies, causas, efeitos, associações, relações e oposições com que se relaciona. Para aquele que se tornaria famoso como o grande educador da Alemanha, estas perguntas simples é que constituíam as verdadeiras questões de método. A construção do conhecimento escolar passou a ser rodeada de uma inusitada economia de meios e processos.

\section{O MÉTODO COMO ATALHO}

Como já deixámos assinalado atrás, não há dúvida que, em todo o 
repertório de Ramus, foi a questão do método que lhe granjeou mais notoriedade. Inserido na tradição pós-Agrícola, as considerações que foi sucessivamente fazendo levaram-no a conceber o método como um hábito da razão que, por meio de considerações as mais diversas e fossem elas quais fossem, não podia jamais perder de vista que lhe cabia a instauração de uma trajetória linear. Na Dialectici commentarii dialectici três, que Ramus publicou em 1546 com Omar Talon, a sua pedagogia prática começava a esboçar-se como o provimento de mecanismos eficazes para a aquisição de conhecimentos. Foi nesse texto que a noção de método apareceu pela primeira vez, numa altura em que se ocupava com a matemática e com Cícero, visto estar então proibido de ensinar filosofia. $\mathrm{Na}$ perspetiva que começou por adotar, methodus deveria equivaler-se a ordo. Quando assim se procedesse, estava certo de que todos os problemas colocados pelas várias situações de aprendizagem se veriam resolvidos, tal como num passe de mágica. $\mathrm{O}$ aluno aprenderia de modo seguro e eficaz se fosse convidado a deslocar-se dos princípios gerais para as partes singulares na recolha da informação. $\mathrm{O}$ conceito corresponde nele à universalização dos critérios da ordem e da utilidade prática na recolha da informação. Explicou-se, então, nestes termos:

O método de ensinar, portanto, é a disposição de várias coisas a partir de princípios gerais e universais em direção às partes singulares, combinadas de modo que a totalidade do tema pode ser mais facilmente ensinado e aprendido. Neste método, apenas isto tem de ser prescrito: que ao ensinar as sentenças (declaratio) gerais e universais elas sejam precedidas de elementos como a definição e algum resumo; depois do qual se segue uma elucidação (explicatio) especial pela distribuição das partes; por último vem a definição das partes singulares e a clarificação através do uso de exemplos idóneos.

Para dizer isto de modo mais simples, vou usar um exemplo familiar. Vamos supor que todas as regras, definições, e divisões da gramática tenham sido confirmadas, que todos os exemplos usados em gramática foram encontrados e que todas estas coisas foram verdadeira e corretamente julgadas e avaliadas. Vamos supor que todas estas prescrições são inscritas em bilhetinhos e misturadas numa urna, como num jogo. Pergunto agora que parte da dialética me ensinaria como juntar todos estes pedaços desordenados de preceitos e como os reduzir 


\begin{abstract}
a uma ordem. Não há aqui necessidade da invenção (inventio) dialética para descobrir os preceitos, pois todos foram encontrados e todas as partes testadas e julgadas. Não há aqui necessidade do silogismo, porque aqui o que é verdade já é compreendido. Portanto, apenas é necessário método e uma disposição segura, e a arte (doctrina) constitui o único método simples que mostra as coisas gerais e universais primeiro, e só depois as especiais e secundárias. Deixemos que o dialético, pela luz do método, escolha primeiro da urna a definição de gramática, pois nada nestas prescrições é mais geral, e coloque-a em primeiro lugar. A gramática é a arte de falar bem e de escrever bem. Depois, deixemo-lo procurar as partes da gramática na mesma urna e localizá-las num segundo momento, depois da definição universal. As partes da gramática são quatro: ortografia, etimologia, sintaxe e prosódia. Deixemo-lo depois separar a definição destas partes (RAMUS cit. ONG, 1983 [1958], p. 245-246, grifo nosso).
\end{abstract}

As suas considerações iniciais partiam sempre do pressuposto segundo o qual a ordem do ensino se observava em toda a vida intelectual e vice-versa. A racionalidade extrema da solução metodológica de Ramus levava-o a acreditar que seria transplantável, por analogia, para todos os ramos do saber, da matemática à filosofia e desta à retórica. É claro que estava a patrocinar estas ideias, de ambiciosa simplicidade, na Universidade de Paris, coração da escolástica e onde a especulação psicológica, a um tempo extremamente formal e mecaniscista, era ainda demasiado sofisticada para se conter nos limites estreitos da sua urna de lotaria. Os ataques ao método de Ramus foram imediatos e lançaram-no no turbilhão da disputa acerca da estrutura interna das ciências e dos fundamentos do raciocínio axiomático. Empreendeu então uma série de revisões a esta posição de partida. As modificações iniciaram-se em 1555 e como que o começaram a fixar nos limites da vulgarização da ciência e não já tanto nos processos da sua própria construção. Dessa nova delimitação estratégica emergiria toda uma nova teoria das prioridades - "método é a disposição pela qual diversas coisas de primeira importância se dispõem em primeiro lugar, as de segunda em segundo, as terceira em terceiro, e assim consequentemente" -, o que fez com que o conceito passasse então a circunscrever-se às prescrições que deviam ser cumpridas no ensino de qualquer segmento do currículo: "método significa que toda a disciplina e disputa é comummente tomada por 
endereçamento e encurtamento de um caminho (adressement \& abrégement)" (RAMUS cit. ONG, 1983 [1958], p. 248). Nestoutro contexto, a ambição de Ramus passou a restringir-se aos domínios da pedagogia, ficando cada vez mais notório que lhe era imperativo encontrar uma fórmula que resistisse à confusão resultante da infinita variedade das coisas do discurso. Método foi-se impondo tão somente como aquele atalho que viabilizaria um afastamento das teorias da demonstração da lógica formal de base aristotélica, garantindo igualmente ao professor que dele dispusesse um meio eficaz de ensinar. A clivagem entre o conhecer próprio à ciência e o conhecer próprio à escola começava a tornar-se mais inteligível.

Anos mais tarde, em 1569, e no lugar dos bilhetinhos que poderiam conter definições e divisões, Ramus estava já a falar de "enunciados homogéneos, cada um deles conhecido por meio de um julgamento apropriado". E em vez de uma mera passagem da definição para as partes e destas até aos derradeiros singulares, defenderia a "progressão dos antecedentes para os consequentes" e, em articulação com ela, "dos universais para os singulares". Na revisão final do manual de dialética, que traz a data de 1572, tomava-se já dos exemplos do ensino das artes e valorizava a clareza dos enunciados para serem memorizados, ao lado do encadeamento das ideias. A sala de aula devia-se transformar-se no espaço social em que o exercício da aquisição do conhecimento se via definitivamente afastado dos emaranhamentos correntes. Não deveria haver nela mais lugar para a dúvida sem resposta. Esta, entendia Ramus, era apanágio de poetas, oradores e historiadores que, desesperados de ensinar as audiências, deitavam mão do "método da dissimulação" e enganavam as multidões dos ignorantes (RAMUS cit. ONG, 1983 [1958], p. 248-249).

Na edição revista da Dialetica, impressa em 1569, afirmou:

Os principais exemplos do método estão no ensino das artes. Aí, apesar de todas as regras serem gerais e universais, existem graus entre elas, na medida em que quanto mais uma regra é geral, tanto mais é precedente. Tais coisas são mais gerais na sua posição e estão em 
primeiro na luminosidade e conhecimento; seguem-se as subalternas, porque são mais próximas na clareza; e assim estas coisas são colocadas em primeiro conforme são melhor conhecidas por natureza (natura notiora), as menos conhecidas são colocadas depois; e finalmente são estabelecidas as mais especiais. Deste modo, a definição geral virá em primeiro, a distribuição a seguir e, se esta última for multifacetada, a divisão em partes integrais vem primeiro, e depois a divisão em espécies. As partes e espécies são então tratadas respetivamente nesta mesma ordem em que são divididas. Se isto significa a intervenção de uma longa explicação, então, ao assumir a parte seguinte ou espécie, toda a estrutura deve ser religada pela mesma transição. Isto irá refrescar e divertir os ouvintes. Porém, para apresentar as coisas de modo mais informal, deve-se usar algum exemplo mais familiar (RAMUS cit. ONG, 1983 [1958], p. 249).

Na última versão do mesmo manual, impressa em 1572, deixou escrito:

Método é a ordem inteligível (dianoia) de vários axiomas homogéneos ordenados um antes do outro de acordo com a clareza da sua natureza, por meio do qual a conformidade de todos, uns com os outros, é julgada e o todo se compromete com a memória. Tal como no axioma se considera verdade e falsidade, e nos silogismos consequência ou falta de consequência, também no método se observa como precedente o que é por si mesmo mais claro (per se clarius), seguindo-se o que é mais obscuro, e se julga a ordem e a confusão em tudo. Deste modo, entre axiomas coloca-se primeiro aquilo que está primeiro em significado absoluto (absoluta notatione), em segundo o que é segundo, em terceiro o que é terceiro, e por aí em diante. Assim, o método prossegue sem interrupção dos universais para os singulares. Apenas por este caminho único se prossegue desde os antecedentes inteira e absolutamente mais conhecidos para a clarificação de efeitos desconhecidos (RAMUS cit. ONG, 1983 [1958], p. 251).

\section{UM NOVO GOVERNO DO OLHAR E DA PALAVRA ORAL}

A necessidade de perceber os vários mecanismos que melhor representariam o conhecimento haveria, ainda, de conduzir Ramus a associar método com outro importante conceito, o de sistema. Foi de facto este que lhe permitiu concluir o seu propósito de conceber a educação formal num quadro de 
eficiência e perfeição natural, até então sem quaisquer precedentes. Não bastaria apenas submeter o infinito do discurso aos princípios da ordem e da complexidade crescente; Ramus especializou-se igualmente nas dicotomias, na distribuição e na disposição, assim como em outras operações diagramáticas que iriam reduzir todo o conhecimento a modelos espaciais bifurcados, a uma taxonomia de tipo arborescente. Os mapas que foi dispondo no interior dos seus manuais constituem uma espécie de telescópio que permitia enxergar de um só lance uma qualquer totalidade, sendo por isso o melhor meio que encontrou para estandardizar, planificar e distribuir os conteúdos da aprendizagem. Dessa forma, deu corpo a um movimento no sentido de que todo o pensamento - e não apenas o do universo - pudesse ser estruturado em modelos espaciais apreendidos pela visão. Imaginou cada arte, gramática incluída, como se fosse um sistema axiomático firmemente organizado. Havemos de reconhecer, outrossim, que os caboucos da teoria curricular contemporânea, e bem assim muitos procedimentos das chamadas boas práticas educativas, estavam já inteiramente supostos na estrutura diagramática proposta por Ramus. Não por acaso, uma das raríssimas aparições do termo currículo ocorreu na versão Professio Regia - publicada como obra póstuma por Thomas Fregius em Basileia no ano de 1576 -, numa Tábua das Artes (Fig. 1), em referência à disciplina de filosofia.

Figura 1 - Tábua das Artes.

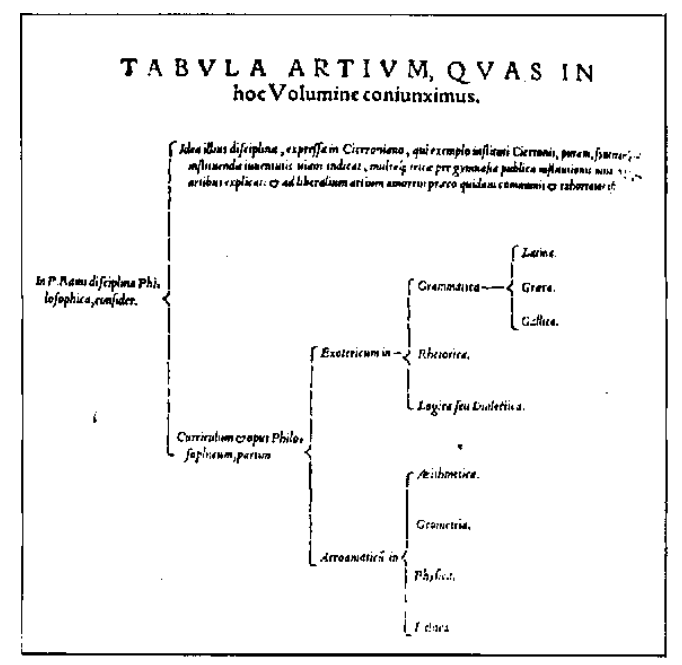

Fonte: Ramus \& Freig (1576, p. 4). 
Foi esta modalidade de representação espacial que permitiu situar o professor como um decisor cuja primeira função é implementar um corpus de conhecimento comprovado, estabelecido e útil. Colocando todo o assunto numa simples folha de papel, a árvore diagramática tornava por seu turno o estudante apto a ver o assunto como um todo e a não ir além do que a imagem lhe devolvia. Até então, nenhuma tecnologia conseguira criar condições tão favoráveis à memorização e ao mimetismo. Na sala de aula concebida pelo ramismo, os exercícios escritos pouco mais seriam do que meras operações lógicas sobre um texto. O dispositivo proposto transformava os procedimentos analíticos que os estudantes deviam desenvolver tão só na procura e descoberta - tipo caça ao tesouro - dos materiais tidos por relevantes para o que estava a ser ensinado. Era por isso de parecer que todos os textos fossem reduzidos a uma coleção de afirmações emblemáticas. A relação dos alunos com a herança textual também se alterava: treinar-se-iam a recolher pequenas parcelas de evidência no acervo dos autores clássicos e a reuni-las com a finalidade de responder a um exercício solicitado pelo seu respetivo professor. Estas novas práticas permitiam reagrupar os excertos de texto e compor uma qualquer narrativa. Nestes termos, Ramus entendia que a composição contínua de um discurso estava dependente de se usar o único e o melhor método de articular as frases - o seu - uma vez que todas as parcelas recolhidas se podiam dispor nas diversas categorias dos seus mapas. O conhecimento diagramático servia assim os propósitos de uma educação prática, isto é, suscetível de "externalizar os vários processos da cognição humana". Os alunos que assim fossem educados "revisitariam, absorveriam e reproduziriam o processo dialético utilizado na Antiguidade pelos mais ilustres pensadores”, como lembram Stephen Triche e Douglas McKnight (2004, p. 47), sempre em face de um mapa constituído por categorias claras e em que qualquer assunto era apreendido como um todo e na relação com o todo. É evidente que esta ramificação planificada do conhecimento escolar haveria de permitir que o currículo se deixasse envolver por objetivos, resultados mensuráveis, avaliações, hierarquias e pelos rankings que dominam a vida presente.

Por fim, o ramismo deve ser entendido como aquele movimento que 
viabilizou um afastamento objetivo da tradição dialógica, desse mundo idiossincrático que se fundara sobre a oralidade. Ao submeter o conjunto das práticas discursivas à realidade objetiva da didática e do livro escolar, deu um impulso decisivo a um deslocamento estrutural em direção ao silêncio na sala de aula. Os diagramas tornaram-se, com Ramus, a base organizativa dos manuais escolares, os quais, por sua vez, se tornariam na base do próprio currículo. A cultura escolar está desde então apta a submergir o aluno num ambiente de discursos audíveis e de objetos visíveis. As noções de conhecimento e de comunicação podiam enfim sofrer uma mutação significativa. O diálogo iria deslocar-se para fora da dialética, à medida em que esta se tornaria pedagogicamente pensável como uma colagem de todos os tipos de coisas objetos e superfícies - que o olho pode apreender. Ficou assim, e de uma vez por todas, desbloqueada a característica mais funda da nossa diferença relativamente ao mundo antigo. A pedagogia ramista está totalmente centrada em anular as vozes e os diálogos entre os atores educativos. Transporta essa especificidade de ignorar o Outro. A sua dialética é, na verdade, uma didática em que se perdeu toda a noção de discurso coloquial, de disputa escolástica ou de diálogo socrático. Constitui uma proposta em que a fala do professor se dirige a um mundo onde os alunos respondem como objetos, ou seja, não dizem nada de volta. As artes do discurso já são, no ramismo, as artes do monólogo. Justamente aquelas que o tempo se encarregaria de tornar nossas nas instituições de ensino que frequentamos e fazemos frequentar.

\section{CONCLUSÃO}

Neste texto procurámos mostrar como o propósito de alargar a escolarização, fazendo-a sair dos círculos restritíssimos das organizações religiosas e da aristocracia europeia da Idade Média e do Renascimento, desbloqueou, a partir do século XVI, uma pedagogização dos conhecimentos dominada pelo objectivo maior do seu disciplinamento interno. Com este ponto 
de partida específico atendemos a um grande consenso político-social da nossa civilização que postula a administração de um único corpus de saber sempre que se trata de massificar e de abrir as portas da escola a novas camadas da população.

Os estabelecimentos de ensino ao longo de Seiscentos - que ficou conhecido para a história da educação como o grande século da didática devolvem-nos já, e em conjunto, um retrato do quotidiano da infância e da juventude no interior de colégios anexos às universidades, com as respectivas classes e salas de aula, nos quais os textos distribuídos para serem trabalhados, mesmo que ainda patenteassem a assinatura dos autores clássicos, eram previamente controlados, selecionados, descontextualizados e expurgados, a fim de se compatibilizarem com as necessidades doutrinais das autoridades religiosas do tempo. Ordem e método, unidade e semelhança, adequação e beatitude estruturaram as opções e vincularam a produção antológica, compendiaria e manualística para uso dos escolares. Cabe insistir que essas mesmas técnicas e esses mesmos procedimentos de extração e constituição do saber legítimo se estenderam a partir das instituições de ensino superior, isto é, do topo para a base do sistema. Desde então as autoridades escolares e pedagógicas não mais cessaram de imaginar formas de sequenciação e complexificação do saber, a que deverão corresponder patamares e ciclos de ensino diferenciados, mas em cujo interior os alunos trabalham a partir dos mesmos artefactos textuais - em geral pouquíssimos, assinale-se -, a perseguir objectivos comuns e a ser classificados de acordo com grelhas e critérios universais que importaram do mundo académico. Círculos cada vez mais alargados da pedagogia europeia, com grande influência nas autoridades escolares, foram convergindo paulatinamente na necessidade de submeter as concepções e os produtos de conhecimento a um autêntico rolo compressor. No interior das instituições de saber, e por meio desta operação, a escrita passou a ser espelho ou um duplo da leitura e não mais um prolongamento dela. De norte a sul da Europa e também no Novo Mundo, os Estados modernos e contemporâneos foram construindo os respectivos sistemas nacionais de ensino não abdicando desta apertada política de governo da cognição, gizada em larga medida pela ação de Petrus Ramus e seus discípulos. 
Os hábitos, hoje incorporados no nosso regime escolar, de dividir, distinguir, analisar e avançar progressivamente, passo por passo, foram pela primeira vez conjugados e ensaiados na Idade Moderna e tiveram em Ramus a sua "personagem conceptual". Na realidade, há uma ideia organizadora na sua proposta: a exigência de em todas as matérias curriculares proceder com ordem e método devia impor-se soberana sobre todas as práticas de ensino e aprendizagem. Não há dúvida que nesta proposta pedagógica se encontra a grande fronteira de demarcação com a escolástica medieval, caraterizada pela disputa; ao mesmo tempo, é nela que igualmente se produz, na sua essência, a abertura de um modelo de civilização, o da escola para todos, construído sobre uma mesma base. Na cultura escolar, ordem significa que se dispõe unicamente das coisas que serão tratadas, o que permite sempre ensinar melhor; método significa que se pode sempre conduzir bem o conhecimento quer quanto ao confuso quer quanto ao distinto e, portanto, que só se tratam problemas bem delimitados e individualizados. Há meio milénio que currículo não é outra coisa senão isto: sistema e graduação. Aprendizagem e criação, aquisição e produção de conhecimentos obedecem, portanto, condições que não são apenas específicas, mas que se seguem trajetórias muito diversas.

Nos últimos séculos, fomos tomando como certo que a função didática não pode prescindir da noção de sistema e de um método que, à uma, garanta o encurtamento coerente dos saberes, postule como eles se desenrolarão nos livros escolares e permita, ainda, a sua tradução em todos os expedientes expositivos na sala de aula.

A pedagogia ramista está totalmente centrada em anular as vozes e os diálogos entre os atores educativos. Transporta essa especificidade de ignorar o Outro. A sua dialética é, na verdade, uma didática em que se perdeu toda a noção de discurso coloquial, de disputa escolástica ou de diálogo socrático. Constitui uma proposta em que a fala do professor se dirige a um mundo onde os alunos respondem como objetos, ou seja, não dizem nada de volta. As artes do discurso já são, no ramismo, as artes do monólogo. Justamente aquelas que o tempo se 
encarregaria de tornar nossas nas instituições de ensino que frequentamos e fazemos frequentar.

\section{REFERÊNCIAS}

DESCARTES, René. Regras para a direção do espírito. Lisboa: Edições 70, 1989 [1628].

FOUCAULT, Michel. Nietzsche, genealogy, history. In: RABINOW, Paul (ed.). The Foucault Reader. Nova Iorque: Pantheon, 1984. p. 76-97.

FOUCAULT, Michel. Vigiar e punir. Petrópolis: Vozes, 1999 [1977].

GRAVES, Frank Pierrepont. Petrus Ramus and the educational reformation of the sixteenth century. Nova Iorque: Macmillan, 1912.

HOTSON, Howard. Commonplace learning: Ramism and its german ramifications. Oxford: Oxford University Press, 2007.

MACK, Peter. Renaissance argument: Valla and Agricola in the traditions of rethoric and dialectic. Leida, Nova Iorque e Colónia: E. J. Brill, 1993.

Ó, Jorge Ramos do. O governo de si mesmo: modernidade pedagógica e encenações disciplinares do aluno liceal (último quartel do século XIX - meados do século XX). Lisboa: Educa, 2003.

ONG, Walter Jackson. Commonplace rhapsody: Ravisus Textor, Zwinger and Shakespeare. In: BOLGAR, Robert Ralph. (ed.). Classical influences on european culture (1500-1700). Cambridge: Cambridge University Press, 1974. p. 91-126.

ONG, Walter Jackson. Ramus, method and the decay of dialogue. Cambridge: Harvard University Press, 1983 [1958].

RAMUS, Petrus. Advertissements sur la reforme de l'Université de Paris. Paris: S. Ed., 1652.

RAMUS, Petrus; FREIG, Johannes Thomas. P. Rami Professio Regia Hoc Est Septem Artes Liberales in Regia Cathedra Per Ipsum Parisijs Apodictico Docendigenere Proposita \& Per Ioan Thomam Freigium in Tabulas Perpetuas... Basileia: Sebastianum Henricpetri, 1576. 
SELLBERG, Erland. Petrus Ramus. In: Stanford Encyclopedia of

Philosophy. Stanford, EUA: Center for the Study of Language and Information (CSLI), Stanford University, 2016. Disponível em:

http://plato.stanford.edu/entries/ramus/. Acesso em: 20 abr. 2018.

TRICHE, Stephen; MCKNIGHT, Douglas. The quest for method: the legacy of Peter Ramus. History of Education, v. 33, n. 1, p. 39-54, 2004.

VARELA, Julia. Genealogy of education. In: POPKEWITZ, Thomas S.; FRANKLYN, Barry M.; PEREYRA, Miguel A. (ed.). Cultural history and education. Nova Iorque: Routledge Falmer, 2001. p. 109-124.

JORGE RAMOS DO Ó é professor associado com agregação no Instituto de Educação (IE) da Universidade de Lisboa (ULisboa), em Lisboa, Portugal e professor convidado na Universidade de São Paulo (USP), onde tem lecionado sobretudo nas áreas da história da educação, história cultural e teoria do discurso. As suas publicações incluem estudos em história cultural e política, com ênfase particular no período do Estado Novo (19331974), bem como em história da educação e da pedagogia em Portugal, analisadas numa longa cronologia (séculos XIX e XX). Para além de diversos artigos, comunicações e trabalhos em co-autoria, tanto em revistas científicas como em monografias, publicou os seguintes livros: O lugar de Salazar: estudo e antologia; Os anos de ferro: o dispositivo cultural durante a política do espírito (1933-1949); O governo de si mesmo: modernidade pedagógica e encenações disciplinares do aluno liceal (último quartel do século XIX - meados do século XX); Modernidade pedagógica: estudos comparados Portugal-Brasil (1820-1960); Ensino liceal (1836-1975); A Universidade de Lisboa, da revolução liberal à atualidade (1834-2000). É atualmente codirector do Doutoramento em Educação Artística oferecido pela Universidades do Porto e de Lisboa. Coordenou projetos de investigação financiados por instituições como a Casa Pia de Lisboa, o Ministério da Educação e a Fundação para a Ciência e a Tecnologia. É editor da Sisyphus - Journal of Education.

E-mail: jorge.o@ie.ulisboa.pt

(D) http://orcid.org/0000-0003-1013-9244

ANA LUÍSA PAZ é atualmente professora auxiliar convidada no Instituto de Educação (IE) da Universidade de Lisboa (Ulisboa), em Lisboa, Portugal. Doutorou-se em 2015 na área de Educação - História da Educação, pelo Instituto de Educação da Universidade de Lisboa, com a tese Ensino da 
Música em Portugal (1868-1930): uma história de pedagogia e do imaginário musical (2014), orientada por Jorge Ramos do Ó (IE-UL) e Denice Bárbara Catani (FE-USP), com auxílio de uma bolsa de doutoramento FCT. Realizou o Mestrado em Sociologia - Sociologia da Educação na Faculdade de Ciências Sociais e Humanas da Universidade Nova de Lisboa (Nova), onde apresentou a tese Identidade, mudança e escola na segunda metade do século XX: textos e atores, sob direção de António Candeias e é licenciada em História pela Faculdade de Letras da Universidade de Lisboa (Ulisboa). Os seus principais interesses de investigação passam, atualmente, pelos temas da pedagogia do ensino superior e da educação artística. Desde o ano 2000 tem estado envolvida em equipas de investigação que se debruçam acerca da escolarização e alfabetização em Portugal, ensino e educação artística e as pedagogias do ensino superior, e onde tem desenvolvido pesquisas tanto em abordagens históricas, como comparativas.

E-mail: apaz@campus.ul.pt

(iD) http://orcid.org/0000-0003-4848-8183

Recebido em: 11 de junho de 2018

Aprovado em: 11 de janeiro de 2019 